\title{
Responsabilidade Social da Educação Superior: Implicações para Estudantes e Comunidade Externa
}

\author{
NáGila Giovanna SiLva Vilela*
}

\begin{abstract}
RESUMO
Os estudos teóricos sobre responsabilidade social começaram a surgir na década de 1950 e ganharam destaque a partir da década de 1970. A definição desse termo é ampla e não há consenso sobre o que definitivamente é a responsabilidade social. No Brasil, a norma ABNT NBR ISO 26000 contém as diretrizes sobre responsabilidade social, conceituando-a como a responsabilidade de uma organização pelas consequências de sua atuação na sociedade e no meio ambiente, por meio de um comportamento íntegro. Quando se trata de instituições de ensino superior, a responsabilidade social possui suas especificidades, pois, nesses casos ela deve estar associada ao tripé ensino, pesquisa e extensão. Nesse sentido, o objetivo do presente artigo é analisar quais ações de responsabilidade social da Universidade Federal do Paraná (UFPR) possuem implicações para os estudantes e a comunidade externa. A fim de atingir esse objetivo, foi feita uma pesquisa no sítio eletrônico da universidade, e, em seguida, realizou-se análise de conteúdo das informações encontradas. Foram identificadas diversas ações de responsabilidade social da UFPR, comprovando que a universidade se preocupa com o bem-estar dos estudantes e da comunidade em seu entorno. Ao final, são ressaltadas algumas limitações do estudo e sugeridas possibilidades de investigação futura. Palavras-chave: Responsabilidade Social. Educação Superior. Universidade.
\end{abstract}

\section{Social Responsibility of Higher Education: IMPLiCATIONS FOR STUDENTS AND THE EXTERNAL COMMUNITY}

\begin{abstract}
The theoretical studies on social responsibility began to emerge in the 50s and gained prominence from the 70s. The definition of this term is broad and there is no consensus on what social responsibility is in fact. In Brazil, the ABNT NBR ISO 26000 standard contains the guidelines on social responsibility, conceptualizing it as the responsibility of an organization for the consequences of its performance in society and the environment, through of a straightforward behavior. When it comes to higher education institutions, social responsibility has its specific characteristics, because in these cases it must be associated with teaching, research and extension activities. In this sense, the purpose of this article is to analyze which social responsibility actions of the Federal University of Paraná have implications for students and the external community. In order to reach this goal, research was done on the university's website and then content analysis of the information found was performed. Several actions of social responsibility of the univer-
\end{abstract}

* Universidade Federal do PaResponsabilidade Social da Educação Superior: Implicações para Estudantes e Comunidade Externaraná. Mestranda em Administração na linha de Estratégia e Análise Organizacional pela Universidade Federal do Paraná. E-mail: nagilavilela@gmail.com . 
sity have been identified, proving that it is concerned with the well-being of its students and the community in its surroundings. At the end, some limitations of the study are highlighted and suggested future research possibilities.

Keywords: Social Responsibility, Higher Education, University.

\section{INTRODUÇÃo}

A mudança na conscientização da sociedade vem modificando o modelo tradicional de atuação empresarial, assentado na ideia puramente de lucratividade, sem considerar a comunidade ao seu redor (KARKOTLI; ARAGÃO, 2004). Nesse contexto, surge o conceito de responsabilidade social.

A responsabilidade social pode ser definida como a responsabilidade de uma organização pelas consequências de sua atuação na sociedade e no meio ambiente, por meio de um comportamento íntegro que: (i) colabora para o desenvolvimento sustentável e para a sociedade em geral; (ii) avalia os interesses dos stakeholders; (iii) está de acordo com as normas internacionais de comportamento; e (iv) integra toda a organização (ABNT NBR ISO 26000, 2010). Em outras palavras, a responsabilidade social requer proatividade das organizações para suscitar o bem-estar da sociedade (SERVA; DIAS, 2016).

No Brasil, a Associação Brasileira de Normas Técnicas (ABNT NBR) ISO 26000 é a norma que dita as diretrizes sobre responsabilidade social. Esta norma foi elaborada pela Comissão de Estudo de Responsabilidade Social (ABNT/CEE-111) com o objetivo de colaborar para o desenvolvimento sustentável (ABNT NBR ISO 26000, 2010). A ABNT NBR ISO 26000 pretende ser útil para todos os tipos de organizações, seja no setor privado ou público, com ou sem fins lucrativos, independentemente do porte, segmento e ambiente de operação (país desenvolvido ou em desenvolvimento) (ABNT NBR ISO 26000, 2010).

Nesse contexto de responsabilidade social, a Responsabilidade Social da Educação Superior (RSES) ou Responsabilidade Social Universitária (RSU) é uma temática que ganhou destaque no âmbito universitário brasileiro a partir de 2004, quando foi incluída como uma das dimensões de avaliação de Instituições de Ensino Superior (IES) pelo Sistema Nacional de Avaliação da Educação Superior (Sinaes) (CALDERÓN, 2006; BOLAN; MOTTA, 2007).

De um lado, o conceito de RSES é visto como oriundo da lógica empresarial, não sendo adequado às IES, visto que essas não são empresas (CALDERÓN, 2006). Por outro lado, pode ser considerado também como um conceito da lógica neoliberal, que, ao responder às expectativas de um projeto de sociedade excludente, torna-se apropriado (CALDERÓN, 2006).

Diante desse contexto, o objetivo do presente artigo é analisar quais ações de responsabilidade social da Universidade Federal do Paraná (UFPR) possuem implicações para os estudantes e a comunidade externa. Para atingir esse objetivo, buscou-se na literatura um embasamento teórico acerca da responsabilidade social e da Responsabilidade Social da Educação Superior, bem como ações concretas da universidade disponibilizadas em seu sítio eletrônico que visam contribuir para o bem-estar dos estudantes e da comunidade em geral. 
Este artigo se justifica devido à amplitude e destaque do tema responsabilidade, que, sendo fundamental para o crescimento e desenvolvimento das empresas (REIS; BANDOS, 2012), também merece ser estudado nas Instituições de Ensino Superior (IES). Além disso, as reflexões a respeito da Responsabilidade Social na Educação Superior podem contribuir para que ações mais generosas sejam implantadas pela instituição e também para que estudantes e a comunidade se inteirem sobre os benefícios que lhes são oferecidos.

O tópico subsequente trata da fundamentação teórica a respeito da responsabilidade social e Responsabilidade Social na Educação Superior (RSES). Posteriormente, são apresentados os procedimentos metodológicos utilizados nessa pesquisa. Passa-se então para os resultados e as discussões, seguido das considerações finais.

\section{FUndaMentaÇão TEÓRICA}

A lógica econômica predominante no século XX pode ser caracterizada por: excessiva utilização de tecnologias, contribuindo para o aumento do desemprego; ênfase no comércio externo e não no doméstico; e reorganização empresarial com intuito de aumentar a produtividade (SIQUEIRA; BINOTTO; SIMIONI, 2010). Esse tipo de atuação empresarial no contexto social foi responsável por ameaças quanto ao futuro e problemas socioeconômicos, sendo as dimensões ambiental e social as mais atingidas (SIQUEIRA; BINOTTO; SIMIONI, 2010).

A mudança na conscientização da sociedade vem modificando o modelo tradicional de atuação empresarial, assentado na ideia puramente de lucratividade, sem considerar a comunidade ao seu redor (KARKOTLI; ARAGÃO, 2004). Isso porque há maior sensibilidade das pessoas em relação às adversidades sociais derivadas das atividades empresariais (SERTEK, 2006). Nesse contexto, surge o conceito de responsabilidade social.

A ideia de responsabilidade social e a preocupação com o papel social da empresa surgiram a partir de Robert Owen, um empresário que no início do século XIX desempenhou aquilo que mais tarde se tornaria o fundamento dos cuidados sociais das empresas (CARVALHO; MEDEIROS, 2013).

O termo "responsabilidade social" foi escrito pela primeira vez em um manifesto assinado por 120 industriais ingleses no final do século XIX (OLIVEIRA, 2002). Esse documento definia que a responsabilidade dos dirigentes da indústria era manter um equilíbrio justo entre os diferentes interesses: dos consumidores, dos funcionários e dos acionistas (OLIVEIRA, 2002).

De acordo com Gomes e Moretti (2007), a ideia central de responsabilidade social empresarial surgiu em 1906 nos Estados Unidos com o trabalho de Charles Eliot. Apesar da proposta de responsabilidade social, o trabalho não desenvolveu nenhum movimento efetivamente (GOMES; MORETTI, 2007). Foi, portanto, "[...] mais uma proposta que morreu no nascedouro" (GOMES; MORETTI, 2007, p. 30). Oliveira (2002) destaca que, além de Charles Eliot, os americanos Hakley (1907) e John Clark (1916) e o inglês Oliver Sheldon (1923) também contribuíram para o início das manifestações da temática no século XX. Apesar disso, o verdadeiro marco para o estudo e debate da temática "responsabilidade 
social" foi em 1953, com o lançamento do livro de Howard Bowen Responsabilities of the businessman, nos Estados Unidos (OLIVEIRA, 2002).

Ainda que os estudos teóricos sobre responsabilidade social tenham começado a surgir na década de 1950, foi a partir da década de 1970 que os trabalhos sobre o tema ganharam relevância (TENÓRIO, 2006). De acordo com Gomes e Moretti (2007), uma evolução do escopo da responsabilidade social no decorrer das décadas pode ser descrita da seguinte maneira: década de 1970: preocupação com o controle ambiental; década de 1980: preocupação com o planejamento ambiental; década de 1990: preocupação com a gestão ambiental; primeira década do século XXI: preocupação com responsabilidade social e ambiental.

Enquanto a responsabilidade social enfatiza as pessoas e o local onde estão inseridas, a responsabilidade ambiental focaliza o meio ambiente (ZARPELON, 2010). Mesmo reconhecendo da importância do controle, planejamento, gestão e responsabilidade ambiental, o foco aqui será dado apenas à responsabilidade social. Isso porque como a proposta dessa pesquisa é analisar as implicações das ações de responsabilidade social de uma universidade para os estudantes e a comunidade externa, a concepção de responsabilidade ambiental não se aplica.

No Brasil, um dos indícios do empenho para que a responsabilidade social empresarial seja destacada é o fato de que a Associação Brasileira de Normas Técnicas (ABNT) foi convidada para liderar, junto com o Instituto Sueco de Normalização (SIS), o Grupo de Trabalho sobre Responsabilidade Social da Organização Internacional de Normalização (Organization of Standardization - ISO) (GOLDSTEIN, 2007). Esse grupo foi responsável por consolidar a ISO 26000. De acordo com essa norma, a responsabilidade social pode ser definida como a responsabilidade de uma organização pelas consequências de sua atuação na sociedade e no meio ambiente (ABNT NBR ISO 26000, 2010).

Oliveira (2002) define a responsabilidade social como a união do objetivo social da empresa e sua atuação econômica. Trata da integração da organização na comunidade como agente social e não apenas econômico (OLIVEIRA, 2002). Nesse sentido,

Ter responsabilidade social é ser uma empresa que cumpre seus deveres, busca seus direitos e divide com o Estado a função de promover o desenvolvimento da comunidade; enfim, é ser uma empresa cidadã que se preocupa com a qualidade de vida do homem na sua totalidade (OLIVEIRA, 2002, p. 205).

Outra definição relevante é a proposta por Zarpelon (2010), que considera a responsabilidade social como a responsabilidade manifesta perante a sociedade em termos de: criação de empregos, oferta de salários decentes, arrecadação tributária justa, aumento da qualidade de vida e todos os outros fatores que podem beneficiar a gestão e a sociedade.

De acordo com as diretrizes da responsabilidade social, as instituições devem atuar levando em considerações os interesses diretos e indiretos da sociedade (SERVA; DIAS, 2016). Melo Neto e Froes (1999) pontuam sete vetores da responsabilidade social de uma empresa: (1) contribuir para o desenvolvimento da sociedade onde está inserida; (2) preservar o meio ambiente; (3) assegurar o bem-estar dos funcionários e seus dependentes, bem como propiciar um ambiente de trabalho agradável; (4) manter uma comunicação 
transparente; (5) proporcionar resultado para os acionistas; (6) cooperar com os parceiros; e (7) satisfazer os clientes.

A essência da responsabilidade social, portanto, está em prevenir prejuízos, promover atividades que contribuam para o desenvolvimento da comunidade em geral e preservar ou fomentar os direitos humanos (SERVA; DIAS, 2016). Dessa forma, as práticas de responsabilidade ou cidadania empresarial manifestam o ideal de que a empresa deve exercer sua função participativa na sociedade, influenciando de maneira proativa e igualitária a comunidade a sua volta (KARKOTLI; ARAGÃO, 2004). Em outras palavras, as atividades das instituições devem estar em consonância com os direitos do consumidor, ambiental, sociais, entre outros (SERVA; DIAS, 2016).

Além das características já mencionadas a respeito da responsabilidade social, ela também pode ter implicações internas e externas. O foco, áreas de atuação, instrumentos e tipo de retorno da responsabilidade social interna e externa estão indicados na Figura 1.

\begin{tabular}{|l|l|l|}
\cline { 2 - 3 } \multicolumn{1}{l|}{} & Respons abilidade Social Interna & Respons abilidade Social Externa \\
\hline Foco & Público interno (empregados e seus dependentes) & Comunidade \\
\hline Áreas de atuação & $\begin{array}{l}\text { Educação; salários e benefícios; as sistência médica, } \\
\text { social e odontológica }\end{array}$ & $\begin{array}{l}\text { Educação; saúde, assistência social; } \\
\text { ecologia }\end{array}$ \\
\hline Ins trumentos & Programas de RH; planos de previdência complementar & $\begin{array}{l}\text { Doações; programas de voluntariado; } \\
\text { parcerias; programas e projetos sociais }\end{array}$ \\
\hline Tipo de retorno & Retorno de produtividade; retorno para os acionistas & $\begin{array}{l}\text { Retorno social propriamente dito; retorno } \\
\text { de imagem; retorno publicitário; retorno } \\
\text { para os acionis tas }\end{array}$ \\
\hline
\end{tabular}

Figura 1 - Responsabilidade Social Interna e Externa

Fonte: Melo Neto e Froes (1999, p. 89).

A responsabilidade social, ainda que aplicada a todas as instituições, tem suas peculiaridades quando se trata de instituições de ensino superior, já que, nesses casos, a responsabilidade deve estar relacionada ao tripé indissociável de ensino, pesquisa e extensão (SERVA; DIAS, 2016). A universidade produz capital cultural e social por meio de suas ações vinculadas a esse tripé de forma socialmente responsável (RIBEIRO; MAGALHÃES, 2014). Nesse sentido, é essencial que as IES estabeleçam medidas capazes de monitorar a prática de responsabilidade social em suas atividades de ensino, pesquisa e extensão, buscando favorecer o bem-estar comunitário (SERVA; DIAS, 2016).

A promoção de educação já não é função suficiente para as instituições de ensino superior (SERVA; DIAS, 2016). A lei atribui às IES uma série de responsabilidades que são inerentes às suas atividades e devem ser cumpridas (SERVA; DIAS, 2016). Conforme o artigo 43 da Lei $n^{\circ}$ 9394, de 20 de dezembro de 2006, a finalidade da educação superior consiste em:

I - estimular a criação cultural e o desenvolvimento do espírito científico e do pensamento reflexivo;

II - formar diplomados nas diferentes áreas de conhecimento, aptos para a inserção em setores profissionais e para a participação no desenvolvimento da sociedade brasileira, e colaborar na sua formação contínua; 
III - incentivar o trabalho de pesquisa e investigação científica, visando o desenvolvimento da ciência e da tecnologia e da criação e difusão da cultura, e, desse modo, desenvolver o entendimento do homem e do meio em que vive;

IV - promover a divulgação de conhecimentos culturais, científicos e técnicos que constituem patrimônio da humanidade e comunicar o saber através do ensino, de publicações ou de outras formas de comunicação;

V - suscitar o desejo permanente de aperfeiçoamento cultural e profissional e possibilitar a correspondente concretização, integrando os conhecimentos que vão sendo adquiridos numa estrutura intelectual sistematizadora do conhecimento de cada geração;

VI - estimular o conhecimento dos problemas do mundo presente, em particular os nacionais e regionais, prestar serviços especializados à comunidade e estabelecer com esta uma relação de reciprocidade;

VII - promover a extensão, aberta à participação da população, visando à difusão das conquistas e benefícios resultantes da criação cultural e da pesquisa científica e tecnológica geradas na instituição.

VIII - atuar em favor da universalização e do aprimoramento da educação básica, mediante a formação e a capacitação de profissionais, a realização de pesquisas pedagógicas e o desenvolvimento de atividades de extensão que aproximem os dois níveis escolares (BRASIL, 2017b).

Levando em consideração a finalidade da educação superior e o conceito de responsabilidade social, percebe-se que as universidades, por serem impulsionadoras de conhecimento e formadoras de profissionais, devem possuir um nível ainda mais elevado de responsabilidade social (REIS; BANDOS, 2012). Além da teoria, o professor precisa se preocupar em cooperar com as práticas sociais (REIS; BANDOS, 2012). Tal atitude visa não somente o bem da comunidade, mas também proporciona ao mercado um profissional capacitado para resolver problemas sociais (REIS; BANDOS, 2012). A ampliação da Responsabilidade Social da Educação Superior (RSES) está relacionada com a defesa de ideais humanistas, em busca de uma universidade empenhada em acabar com a pobreza e construir uma sociedade justa e democrática (CALDERÓN, 2006).

A ponte entre a universidade e a sociedade que efetiva o compromisso social da universidade e a consideração ética a respeito da dimensão social do ensino é a extensão universitária (CALDERÓN, 2006). Os projetos sociais concebidos pelas universidades também são exemplos de pontes (REIS; BANDOS, 2012). Nesses casos, inicialmente o problema é identificado, e, em seguida, é traçado um projeto de ação entre a universidade, professores, estudantes e a comunidade (REIS; BANDOS, 2012).

Destaca-se que o reconhecimento de um problema social é o primeiro passo para que um projeto possa ser estabelecido. Por essa razão é importante que mais do que a mera transmissão de conteúdo, as universidades devem estar cientes da realidade que permeia a sociedade (REIS; BANDOS, 2012). O reconhecimento dos problemas sociais colabora para que os indivíduos reflitam, critiquem e desenvolvam competências em um grau mais elevado (REIS; BANDOS, 2012). Assim, a exposição do estudante à prática na faculdade contribui para uma visão mais humanitária e realista do mundo (REIS; BANDOS, 2012). 
Complementarmente às suas atividades básicas de ensino, pesquisa e extensão, é atribuição da universidade "[...] desenvolver mentes humanas proativas para o pleno exercício da cidadania, através de ações criativas capazes de construir sociedades socialmente responsáveis e economicamente sustentáveis" (RIBEIRO; MAGALHÃES, 2014, p. 135).

A necessidade de as IES praticarem a responsabilidade social está expressa nas dimensões de avaliação do Sinaes, criado pela Lei no 10.861 de 14 de abril de 2004 (SERVA; DIAS, 2016; BRASIL, 2017a). Esse sistema de avaliação promove a avaliação das instituições, dos cursos do desempenho dos estudantes (BRASIL, 2017a). Entre os itens avaliados estão: a missão e o plano de desenvolvimento institucional; a política para o ensino, a pesquisa, a pós-graduação, a extensão e as respectivas formas de operacionalização; a responsabilidade social da instituição; a comunicação com a sociedade; as políticas de pessoal; organização e gestão da instituição; infraestrutura física; planejamento e avaliação; políticas de atendimento aos estudantes; e sustentabilidade financeira (BRASIL, 2017a).

Para finalizar essa sessão de fundamentação teórica, ressalta-se que a responsabilidade social não é um fenômeno exclusivo da área de educação e universitária, mas sim um conceito que tem sido disseminado no âmbito das ciências políticas, da economia, da administração e da gestão, e, principalmente, na esfera das reformas de Estado, dos sistemas econômicos e dos sistemas políticos (RIBEIRO; MAGALHÃES, 2014).

Apresentadas essas questões acerca da responsabilidade social e da RSES, o tópico a seguir apresenta os procedimentos metodológicos norteadores da pesquisa.

\section{Procedimentos metodológicos}

Quanto à abordagem, a pesquisa é qualitativa visto que a preocupação está em entender as particularidades do objeto de estudo (GERHARDT; SILVEIRA, 2009), isto é, as ações de responsabilidade social da UFPR que possuem implicações para os estudantes e a comunidade externa. Em relação aos objetivos, trata de um estudo descritivo, uma vez que a responsabilidade social da universidade será analisada sem que haja manipulação de nenhum fenômeno ou variável (CERVO; BERVIAN; SILVA, 2007).

A técnica de coleta de dados utilizada foi a análise de documentos disponíveis no sítio eletrônico da UFPR. O website da universidade foi considerado a principal fonte de análise devido ao fato de a UFPR não ter um departamento ou relatório específico de responsabilidade social. O primeiro passo dessa análise foi realizar um levantamento geral das informações disponíveis no website da universidade, atentando-se às ações benéficas para estudantes e comunidade externa (ainda que não estivessem claramente descritas como "ações de responsabilidade social"). Em seguida, as informações relevantes foram transcritas para um documento do Word e organizadas de acordo com o público favorecido pelas atividades.

Os dados foram analisados com base na técnica de análise de conteúdo (BARDIN, 2004) e comparados com a teoria exposta na fundamentação teórica desse mesmo trabalho. As discussões estão descritas a seguir. 


\section{Resultados E discuSSÃo}

Nesta sessão são apresentadas e discutidas as ações de responsabilidade social da UFPR que possuem implicações para estudantes e para a comunidade externa.

Inicialmente, destaca-se que a universidade reconhece sua função social, sendo essa elucidada na própria apresentação em seu sítio eletrônico. A função social da universidade é valorizada por meio do tripé Ensino, Pesquisa e Extensão, pois todo ensino, pesquisa e atividade de extensão deve devolver para a comunidade os recursos públicos que a permitem existir enquanto Instituição Federal de Ensino Superior, seja em forma de conhecimento, tecnologia e/ou cultura (UFPR, 2017). Nesse sentido, percebe-se que, conforme apresentado por Ribeiro e Magalhães (2014), a universidade é consciente de que a produção de capital cultural e social por meio de suas atividades é vinculada a esse tripé de forma socialmente responsável.

Quando considerados a missão, princípios e valores da UFPR, constata-se que estão alinhados com a finalidade da educação superior expressa no artigo 43 da lei 9394/2006. A missão fomentar, construir e disseminar o conhecimento, contribuindo para a formação do cidadão e desenvolvimento humano sustentável (UFPR, 2017) é compatível com o item VIII da lei que aborda a necessidade de atuar em favor da universalização e do aprimoramento da educação básica, mediante a formação e a capacitação de profissionais (BRASIL, 2017b).

Os princípios universidade pública, gratuita, de qualidade e comprometida socialmente; indissociabilidade entre Ensino, Pesquisa e Extensão; liberdade na construção e autonomia na disseminação do conhecimento; e respeito a todas as instâncias da sociedade organizada (UFPR, 2017) associam-se principalmente com a ideia do item I da lei sobre o estímulo à criação cultural e o desenvolvimento do espírito científico e do pensamento reflexivo (BRASIL, 2017b).

Em relação aos valores da UFPR, o comprometimento com a construção do saber e formação de profissionais competentes e compromissados socialmente (UFPR, 2017) vincula-se ao item II da lei no que diz respeito a formar diplomados nas diferentes áreas de conhecimento, aptos a participar no desenvolvimento da sociedade brasileira, e colaborar na sua formação contínua (BRASIL, 2017b). A gestão participativa, dinâmica e transparente comprometida com melhores condições de trabalho e qualidade de vida (UFPR, 2017) pode contribuir para que os problemas do mundo sejam conhecidos, bem como sejam prestados serviços especializados à comunidade (item VI) (BRASIL, 2017b).

Para os estudantes, a ideia de responsabilidade social começa no processo seletivo, em que a raça, o gênero, a nacionalidade e qualquer outro tipo de discriminação não têm lugar. Das vagas oferecidas pela UFPR, $50 \%$ estão em conformidade com o sistema de cotas de que trata a Lei $n^{\circ} 12.711 / 12$, o Decreto $n^{\circ} 7.824$ e a Portaria $n^{\circ} 18 / 2012-$ MEC (NC UFPR, 2016). Além disso, em cada curso há uma vaga destinada para pessoa com deficiência, conforme a Resolução $\mathrm{n}^{\mathrm{o}}$ 70/08-COUN, sendo priorizados aqueles que não possuem nenhum curso superior (NC UFPR, 2016). 
A universidade também recebe estudantes estrangeiros, tendo desenvolvido um forte programa de internacionalização, com atividades contínuas de cooperação e intercâmbio acadêmico e científico (UFPR, 2017). Atualmente a UFPR atrai estudantes de pós-graduação latino-americanos, africanos, asiáticos, europeus e norte-americanos (UFPR, 2017). Mais de 100 programas de cooperação internacional são estabelecidos com países da Ásia, América do Norte e Europa, sendo destacadas as múltiplas parcerias efetivas com universidades francesas e alemãs (UFPR, 2017).

No que diz respeito à extensão aberta à população (item VII da lei 9394/2006) (BRASIL, 2017b), na UFPR a articulação entre o ensino e a pesquisa possibilita a relação transformadora entre a Universidade e os diversos setores da sociedade (PROEC, 2017). Isso porque os resultados das atividades de extensão reafirmam e materializam os compromissos éticos e solidários da universidade (PROEC, 2017). Aliado ao valor de uma cultura de planejamento e avaliação contínua da vida universitária (UFPR, 2017), a UFPR oferece serviços de atendimento à saúde por meio do Hospital das Clínicas (HC), Casa de Atenção à Saúde (casa 3), Centro de Psicologia Aplicada (CPA) e Serviço de Triagem do Curso de Odontologia da UFPR.

O HC é o maior programa de extensão da universidade e conta com outros projetos lá desenvolvidos (UFPR, 2017). Além disso, nas três unidades (Hospital de Clínicas, Hospital Veterinário e Maternidade Victor Ferreira do Amaral) do HC, o hospital escola da UFPR atende estudantes e a comunidade externa (UFPR, 2017).

Por meio da Casa 3, a UFPR presta serviços de: consulta médica eletiva nas especialidades de clínica médica, pediatria, ginecologia e psiquiatria; assistência de enfermagem: coleta de exames Papanicolau, curativos, administração de medicações, pré-consulta com orientações e encaminhamentos e administração de vacinas (dupla e hepatite); assistência odontológica primária (restaurações e profilaxia); assistência social (acompanhamento domiciliar e acadêmico) (PROGEPE, 2017). A Casa 3 é o sistema de atendimento à saúde oferecido à comunidade universitária (PROGEPE, 2017).

Ainda no que diz respeito à saúde, o CPA é um serviço-escola do curso de Psicologia da UFPR que busca unir as necessidades dos pacientes e as necessidades de formação dos estagiários (UFPR, 2017). É, portanto, um ambiente de treinamento, aperfeiçoamento e pesquisa para professores e alunos de graduação e pós-graduação (UFPR, 2017). Em serviço aberto a crianças, adolescentes e adultos da comunidade externa, os alunos de Psicologia (supervisionados pelos professores responsáveis) atendem casos relacionados com: psicoterapia individual, avaliação e reabilitação neuropsicológica, situações de perda/luto, problemas relacionados ao uso de álcool e outras drogas, avaliação e reabilitação em traumatismo craniano e acidente vascular cerebral (AVC), neuropsicologia e atenção precoce para crianças com risco de problemas de desenvolvimento e suas famílias, clínica para crianças e adolescentes com dificuldades e transtornos de aprendizagem, orientação profissional, grupo de orientação para pais, grupo terapêutico para crianças e adolescentes, e grupo de apoio à Síndrome Pós-Pólio (paralisia infantil) (UFPR, 2017). 
Tem-se ainda o Serviço de Triagem do Curso de Odontologia da UFPR, programa em que os alunos de odontologia da universidade prestam serviços à comunidade nos procedimentos que aliam as necessidades dos pacientes e as necessidades de treinamento dos alunos (UFPR, 2017). É um Centro de Referência em Odontologia para o Sistema Único de Saúde de Curitiba e Área Metropolitana (UFPR, 2017).

No que diz respeito à alimentação, a universidade conta com o Restaurante Universitário (RU), que atende a comunidade acadêmica (docentes, discentes e servidores técnico-administrativos) e não acadêmica (comunidade externa) desde 1961, fornecendo com café da manhã, almoço e jantar (UFPR, 2017). Os valores são variáveis de acordo com a categoria em que o indivíduo se encaixa (docente, discente etc.), não ultrapassando o valor de R $\$ 10,00$ (UFPR, 2017). Alguns bolsistas (por exemplo, PROBEM) e residentes de Medicina e Medicina Veterinária não pagam por nenhuma das refeições (UFPR, 2017).

O PROBEM é um programa criado para auxiliar os estudantes com dificuldade financeira para se manter no curso. São oferecidos benefícios relacionados à permanência (R \$400 mensais), refeição (isenção das taxas nas refeições, três refeições por dia, sete dias por semana), moradia ( $\mathrm{R} \$ 275,00$ mensais) e creche ( $\mathrm{R} \$ 200,00$ mensais para estudantes que possuem filhos na faixa etária de 0 a 6 anos incompletos) (PRAE, 2017).

O Programa de Bolsa Permanência do MEC (PBP/MEC) é outra iniciativa para apoiar financeiramente os estudantes. Aqueles que estão matriculados em cursos (Biomedicina, Farmácia, Fisioterapia, Medicina, Medicina Veterinária de Palotina e Oceanografia) com carga horária média diária maior ou igual a cinco horas em situação de vulnerabilidade socioeconômica pode receber $\mathrm{R} \$ 400,00$ e estudantes indígenas e quilombolas, $\mathrm{R} \$ 900,00$ (PRAE, 2017).

Outra modalidade de bolsa é o PROMISAES, destinada a estudantes estrangeiros regularmente matriculados em Cursos de Graduação ou de Ensino Profissionalizante e que possuem bom desempenho acadêmico e fragilidade socioeconômica (PRAE, 2017). Essa é uma forma de contribuir para que os estudantes se mantenham no curso (PRAE, 2017).

Ainda no que diz respeito a apoios financeiros, a universidade conta com o Programa de Apoio a Eventos Estudantis. Com esse programa os estudantes têm possibilidade de participar de eventos em cidades distintas ao seu campus, bem como realizar eventos estudantis, seja de caráter didático-científico, político-acadêmico, eventos de natureza artístico-cultural ou ainda, eventos esportivos (PRAE, 2017).

Além dos auxílios à saúde, alimentação e financeiros, a UFPR também oferece suporte na adaptação de estudantes vindos de outras cidades para estudar nos campi ou campus da universidade em Curitiba (PRAE, 2017). Apesar de não envolver aspectos financeiros, o Grupo de Estudantes Forasteiros é uma ação desenvolvida pela Pró-Reitoria de Assuntos Estudantis (PRAE) e criado a partir da dificuldade percebida de muitos alunos em se ajustar à cidade e à própria instituição (PRAE, 2017). Assim, por meio do diálogo, os estudantes podem aprender como enfrentar e superar suas principais dificuldades (PRAE, 2017).

Algumas outras ações e programas educacionais e culturais que beneficiam a comunidade externa devem ser evidenciadas. A Rede Cedes Paraná desenvolve projetos de 
extensão e pesquisas sobre políticas públicas para esporte e lazer na sociedade, o que contribui diretamente para a gestão pública (UFPR, 2017). O Núcleo de Assessoria Pedagógica (NAP) visa aproximar professores e futuros professores de línguas estrangeiras dos ensinos fundamental, médio e superior, de universidades e escolas de idiomas (UFPR, 2017). O Núcleo de Estudos Afro-Brasileiros (NEAB) busca articular e promover atividades de ensino, pesquisa e extensão referentes ao campo de estudos afro-brasileiros (UFPR, 2017).

Por meio do Núcleo Interdisciplinar de Meio Ambiente e Desenvolvimento Universidade Federal do Paraná (NIMAD) são desenvolvidas atividades de pesquisa, extensão e formação com o intuito de integrar as questões sociais e ambientais às estratégias de desenvolvimento sustentável (UFPR, 2017). O Núcleo Interdisciplinar de Estudos sobre o Terceiro Setor (NITS) ao desenvolver estudos, pesquisas e extensão relacionados com o Terceiro Setor e suas organizações, amplia a inserção da UFPR na sociedade brasileira (UFPR, 2017).

O programa Ciência Vai à Escola proporciona meios e instrumentos para que o processo de ensino e aprendizagem da Ciência seja modificado (UFPR, 2017). Para isso, são oferecidos cursos, oficinas, exposições científicas, participações em práticas interativas, interpretação e estudo experimental de materiais biológicos, entre outros (UFPR, 2017). Física: Brincando e Aprendendo é outra ação da UFPR que integra os alunos de graduação em Licenciatura em Física e a comunidade (UFPR, 2017). São feitas demonstrações de fenômenos físicos para estudantes de Física e Ciências das escolas públicas da região de Curitiba (UFPR, 2017).

O Núcleo de Comunicação e Educação Popular aproxima os estudantes de Comunicação Social da comunidade por meio de movimentos sociais e populares (UFPR, 2017). Por último, o Núcleo de Prática Jurídica visa garantir os direitos humanos dos cidadãos, prestando serviços de assessoria jurídica nas áreas Cível, Penal, Trabalhista e Previdenciária (UFPR, 2017).

Destaca-se que as ações de responsabilidade social voltadas aos estudantes e à comunidade que foram destacadas nessa sessão não representam a totalidade da atuação da UFPR. Outras atividades da universidade têm potencial e de fato contribuem para o bem-estar de estudantes, docentes, servidores e para a sociedade em geral. Devido ao escopo dessa pesquisa as ações foram limitadas, no entanto, cabe ressaltar que as atividades da UFPR podem ser acompanhadas no sítio eletrônico da universidade e nos relatórios de gestão disponibilizados pela Pró-Reitoria de Planejamento, Orçamento e Finanças. Posto isso, no tópico seguinte encontram-se as considerações finais a respeito desse artigo.

\section{CONSIDERaÇões FINAIS}

A grande missão da educação superior é ampliar a visão e a capacidade de interpretação dos estudantes, prepará-los para trabalhar de forma criativa em prol do desenvolvimento da sociedade, estimular que o conhecimento existente seja avaliado criticamente e procurar as melhores maneiras para que os indivíduos possam conceber uma boa sociedade (FITZPATRICK, 1988). Sendo assim, considerando as ações de responsabilidade social da UFPR destacadas na sessão anterior, bem como relacionando-as com as finalidades 
e missão do ensino superior, é possível averiguar que a universidade se preocupa com o bem-estar dos estudantes e da comunidade em seu entorno.

Para os estudantes, as contribuições vão desde auxílio financeiro até auxílio psicológico e de adaptação à instituição e à cidade. Para a comunidade, as vantagens incluem assistência médica, alimentação de baixo custo, cursos, oficinas, auxílio jurídico, entre outros.

Este trabalho defende a ideia de que a universidade deve estar constantemente ciente e envolvida nas dificuldades enfrentadas pelos estudantes e pela comunidade (independentemente de seu caráter, seja financeiro, econômico, social etc.), buscando contribuir para a melhoria da qualidade de vida dos mesmos.

A forma de coleta de dados, que incluiu apenas análise de documentos disponíveis no sítio eletrônico da universidade pode ser considerada uma limitação desse estudo. Além disso, o fato de que não foi verificado se efetivamente todos os programas e núcleos relacionados à responsabilidade social estão em funcionamento também é um elemento limitador.

Finalmente, estudos futuros podem buscar novas fontes de coletas de dados bem como comparar as ações de responsabilidade social de diferentes universidades, sejam elas públicas ou privadas.

\section{REFERÊNCIAS}

ABNT NBR ISO 26000. Diretrizes sobre responsabilidade social. 2010.

BARDIN, L. Análise de conteúdo. 3. ed. Lisboa: Edições 70, 2004.

BOLAN, Valmor; MOTTA, Márcia Vieira. Responsabilidade Social no Ensino Superior. Revista de Educação 2007.

BRASIL. Lei no 10.861 , de 14 de abril de 2004. Institui o Sistema Nacional de Avaliação da Educação Superior - SINAES e dá outras providências. Disponível em: http://www.planalto.gov.br/ ccivil_03/_ato2004-2006/2004/lei/110.861.htm. Aceso em: 25 mar. 2017a.

BRASIL. Lei no 9.394, de 20 de dezembro de 1996. Estabelece as diretrizes e bases da educação nacional. Disponível em: http://www.planalto.gov.br/ccivil_03/Leis/L9394.htm. Acesso em: 25 mar. $2017 b$.

CALDERÓN, Adolfo Ignacio. Responsabilidade Social Universitária: contribuições para o fortalecimento do debate no Brasil. Revista da Associação Brasileira de Mantenedoras de Ensino Superior, v. 24, n.36, p. 7-22, 2006.

CARVALHO, Osório; MEDEIROS, Janann. Racionalidades Subjacentes às Ações de Responsabilidade Social Corporativa. Organizações \& Sociedade, v. 20, n. 64, p. 17-36, 2013.

CERVO, Amado Luiz.; BERVIAN, Pedro Alcino.; SILVA, Roberto. Metodologia científica. 6. ed. São Paulo: Pearson Prentice Hall, 2007.

FITZPATRICK, Margaret Mary. Social Responsibility in Higher Education. NASPA Journal, v. 25, n. 3, p. 191-194, 1988.

GERHARDT, Tatiana Engel; SILVEIRA, Denise Tolfo. Métodos de pesquisa. Porto Alegre: Editora da UFRGS, 2009. 
GOLDSTEIN, Ilana. Responsabilidade social: das grandes corporações ao terceiro setor. São Paulo: Ática, 2007.

GOMES, Adriano; MORETTI, Sérgio. A responsabilidade e o social: uma discussão sobre o papel das empresas. São Paulo: Saraiva, 2007.

KARKOTLI, Gilson; ARAGÃO, Sueli Duarte. Responsabilidade Social: uma contribuição à gestão transformadora das organizações. 2. ed. Petrópolis: Editora Vozes, 2004.

MELO NETO, Francisco Paulo; FROES, César. Responsabilidade Social \& Cidadania Empresarial. 2. ed. Rio de Janeiro: Qualitymark, 1999.

NC UFPR. Edital no 24/2016 - NC/PROGRAD. 2016. Disponível em: http://www.nc.ufpr.br/concursos_institucionais/ufpr/ps2017/documentos/edital_242016_nc.pdf. Acesso em: 27 mar. 2017.

OLIVEIRA, Fábio Risério Moura. Relações públicas e a comunicação na empresa cidadã. In: Vários autores. Responsabilidade social das empresas. São Paulo: Peirópolis, 2002. p. 195-228.

PRAE. Pró-Reitoria de Assuntos Estudantis. Disponível em: http://www.prae.ufpr.br/prae/. Acesso em: 27 mar. 2017.

PROEC. Pró-reitoria de Extensão e Cultura. O que é extensão universitária?. Disponível em: http://www.proec.ufpr.br/links/extensao.html. Acesso em: 27 mar. 2017.

PROGEPE. Central de Atenção à Saúde - Casa 3. Disponível em: http://www.progepe.ufpr.br/ progepe/?page_id=91. Acesso em: 27 mar. 2017.

REIS, Amanda Lima; BANDOS, Melissa Franchini Cavalcanti. A Responsabilidade Social de Instituições de Ensino Superior: Uma Reflexão Sistêmica Tendo em Vista o Desenvolvimento. Revista Gestão \& Conhecimento, Edição Especial, 2012.

RIBEIRO, Raimunda da Cunha; MAGALHÃES, Antônio M. Política de responsabilidade social na universidade: conceitos e desafios. Educação, Sociedade \& Culturas, n. 42, p. 133-156, 2014.

SERTEK, Paulo. Responsabilidade social e competência interpessoal. Curitiba: Ibpex, 2006.

SERVA, Fernanda Mesquita; DIAS, Jefferson Aparecido. Responsabilidade Social nas Instituições de Ensino Superior: Entre o Biopoder e a Biopolítica. Revista Argumentum, v. 17, p. 413-433, 2016.

SIQUEIRA, Elisabete Stradiotto; BINOTTO, Erlaine; SIMIONI, Flávio José. Responsabilidade Social em uma Perspectiva Internacional: a Busca de uma Possibilidade de Conciliação entre o Econômico e o Social. In: SPERS, Valéria Rueda Elias; SIQUEIRA, Elisabete Stradiotto. Responsabilidade Social: conceitos, experiências e pesquisas. Itu: Ottoni Editora, 2010. p. 33-49.

TENÓRIO, Fernando Guilherme. Responsabilidade Social Empresarial: Teoria e Prática. 2. ed. Rio de Janeiro: Editora FGV, 2006.

UFPR. Universidade Federal do Paraná. Disponível em: http://www.ufpr.br/portalufpr/. Acesso em: 27 mar. 2017.

ZARPELON, Márcio Ivanor. Gestão e Responsabilidade Social: Atualizado em ISO 26.000, Sustentabilidade, Modelo Ethos e MEG. Rio de Janeiro: Qualitymark, 2010.

Submetido em: 29-9-2017

Aceito em: 15-7-2020 